\title{
What accounts for 'England's green and pleasant land'? A panel data analysis of mental health and land cover types in rural England
}

I. Alcock ${ }^{a, *}$, M.P. White ${ }^{a}$, R. Lovell ${ }^{a}$, S.L. Higgins ${ }^{a}$, N.J. Osborne ${ }^{a}$, b, K. Husk ${ }^{a, c}$, B.W.

Wheeler $^{\mathrm{a}}$

a. European Centre for Environment and Human Health, University of Exeter Medical School, Knowledge Spa, Royal Cornwall Hospital, Truro, Cornwall TR1 3HD, United Kingdom

b. Department of Pharmacology, School of Medical Sciences, Sydney Medical School, University of Sydney, Sydney 2006, Australia

c. Plymouth University Peninsula Schools of Medicine and Dentistry, Drake Circus, Plymouth, Devon PL4 8AA, United Kingdom

*Corresponding author. Tel.: +44 01872258151.

E-mail addresses: i.alcock@exeter.ac.uk (I. Alcock), Mathew.White@exeter.ac.uk(M.P. White), R.Lovell@exeter.ac.uk (R. Lovell), S.Higgins@exeter.ac.uk(S.L. Higgins), N.J.Osborne@exeter.ac.uk (N.J. Osborne),kerryn.husk@plymouth.ac.uk (K. Husk), B.W.Wheeler@exeter.ac.uk(B.W.Wheeler).

\section{Keywords:}

Green space

Land cover

Mental health

Wellbeing

Rural

British Household Panel Survey 


\section{Abstract}

Exposure to green space is associated with a variety of positive health states. Research to date has focused primarily on 'generic' green space in urban areas, where green space is relatively scarce and where it is dominated by playing fields and parks. The current research adds to our understanding with an examination of relationships between different types of green space and mental health in rural areas in England (approximate rural population $=4$ million). The aggregate land cover classes of Land Cover Map 2007 were linked to rural residential areas (Lower-level Super Output Areas) and then linked to rural participants $(n=$ 2020) in the 18-year longitudinal British Household Panel Survey. Random effects regression of mental health (as measured by GHQ12 scores) against land cover enabled effects to be simultaneously estimated from both mean between-individual differences and from within-individual differences over time. The nine natural land cover classes (Broadleaved woodland; Coniferous woodland; Arable; Improved grassland; Semi-natural grassland; Mountain, heath and bog; Saltwater; Freshwater; Coastal) were not significantly associated with differences in mental health between individuals. However, significant relationships were observed between some types of land cover and within-individual change in mental health amongst individuals who relocated during the 18 annual waves of the panel. These findings indicate the presence of important health related ecosystem services from different land cover types that have not previously been investigated and which help more effective spatial planning and land use management. 


\section{Introduction}

\section{Overview}

William Blake's phrase "England's green and pleasant land" (Blake, 1804) has become a byword for those aspects of the English countryside which are idealised in the national psyche. Although the rural landscape of today is very different from the "pleasant pastures" and "mountains green" which Blake explicitly linked to spiritual well-being at the dawn of the industrial age, the idea that physical landscape is intimately involved in well-being persists, and is increasingly the subject of multi-disciplinary empirical research (Hartig, et al., 2014).

Exposure to the natural environment has been associated with better self-reported general health (Maas, et al., 2006; Mitchell and Popham, 2007), lower prevalence of diagnosed morbidities (Maas, et al., 2009), increased longevity (Takano, et al., 2002), less premature mortality (Mitchell and Popham, 2008) more rapid recovery from illness (Ulrich, 1984), higher levels of psychological well-being (Kaplan and Kaplan, 1989; White et al., 2013a), and lower levels of anxiety and depression (Beyer, et al., 2014; de Vries, et al., 2003; Maas, et al., 2009; van den Berg, et al., 2010). Moreover, the research is starting to inform the development of tangible health promotion strategies and practices (St Leger, 2003). However, to date, much of the evidence of a relationship between natural environments and mental health and well-being has focused on urban rather than rural communities (Alcock, et al., 2014; Astell-Burt, et al., 2014). The aim of the current research was to begin to redress this balance.

The issue of rural mental health is important because a significant minority of people live in rural residential areas. In England, around 4.2 million people live in areas classified as rural (8\% of the population). Despite a long-term trend towards urbanization, data compiled by the UN Department of Economic and Social Affairs suggests there are currently close to 200 million people living in rural areas in Europe. Whilst there are suggestions that the 
prevalence of common mental disorders such as anxiety and depression are lower in rural than urban areas (Weich, et al., 2006), there are substantial differences in their prevalence across English villages which are not accounted for by variation between individuals or by area levels of socio-economic deprivation (Riva, et al., 2009). This suggests that other aspects of rural areas, potentially including the nature of the physical environment, may be related to mental health. Furthermore, the treatment of poor mental health in rural communities may be more challenging due to geographical barriers, social isolation and to rural cultural beliefs on help-seeking for mental illness. These factors may partially explain why suicide rates also tend to be higher in some rural areas (Gunnell, et al., 2012). Against this backdrop, a better understanding of factors which may support more positive mental health in rural areas is clearly desirable.

As to why previous research into the relationships between natural environments and mental health has been neglected in rural areas, it is likely to be, in part, because the focus has been on the quantity of 'available green space', which is arguably more important for built-up urban areas where green spaces may be scarce, than in rural areas where it is abundant. Previous epidemiological research, for instance, has generally dichotomised land cover as green/not green (Jorgensen and Gobster, 2010) and there is awareness that this dichotomy is particularly limited for rural areas because there is "too little variation in the quantity of green space" (Ord, Mitchell and Pearce, 2013) between rural areas for this comparison to often be meaningful (see also Astell-Burt, et al., 2014). However, although green spaces in towns and cities are generally dominated by parks, what constitutes green space in rural areas tends to be more mixed (e.g. farmland, moorland) and as yet we know relatively little about the importance of this variation in green space in rural settings. In other words, type and quality, rather than just quantity, may be particularly relevant for mental health in rural settings.

\section{Current Research}

Post-review pre-publication draft. Published as Alcock, I., White, M.P., Lovell, R., Higgins, S.L., Osborne, N.J., Husk, K., Wheeler, B.W., 2015. What accounts for 'England's green and pleasant land'? A panel data analysis of mental health and land cover types in rural England. Landscape and Urban Planning 142, 38-46. 
It is suggested that results from landscape preference studies, where work with photographs gives evidence of preferences for more natural landscapes over more urban landscapes, may be related to the potential for natural environments to reduce stress and improve wellbeing (Hartig and Evans, 1993; van den Berg, et al. 2003). Drawing on insights from the landscape preferences literature on differential preferences for different land cover types, we hypothesised that the presence of certain types of natural space environment in rural areas, such as woodlands and aquatic environments, may be linked to more positive mental health outcomes. These hypotheses were tested using data from a sample of residents of rural England who took part in a longitudinal panel survey between 1991 and 2008. Using data of this kind allowed us to do two things. First, similar to the cross-sectional approach used in most previous work looking at green space and mental health in urban areas, we were able to compare the individual average mental-health of people who lived in one type of rural area (e.g. with high proportions of woodland, or of arable) with that of those living in a different type of rural area (e.g. with low proportions of woodland, or of arable). Second, due to the longitudinal nature of the data we were able to track people's well-being over many years, including among those who moved from one rural area to another rural area. Controlling for other changes in their lives, therefore, we were able to estimate the effect of different rural land cover on the same individuals over time. This second type of analysis enables us to account for factors such as personality and early life experiences. Specifically, crosssectional correlations may merely reflect the fact that different sorts of people, with better mental health, have greater exposure to natural environments, rather than point to a causal relationship. In contrast, associations based on within-individual differences eliminate confounding from individual level heterogeneity (Antonakis, et al., 2010).

By examining the relationships between mental health and a variety of land cover types in different rural residential areas, our work has parallels to pioneering research conducted in Sweden using the Scania Green Score (SGS). The SGS identified a set of characteristics 
which Swedish people regarded as important in green space and operationalised these using criteria measurable from land cover, land use and topography datasets (Skärbäck, et al., 2012). SGS was found to be related to neighbourhood satisfaction, physical activity, Body Mass Index, vitality in women, and self-rated health (Björk, et al., 2008; de Jong, et al., 2012). A further study showed that interaction between some of the SGS component green space characteristics and being physically active was associated with reduced risk of poor mental health in women (Annerstedt, et al., 2012). However, although the work from Sweden used land cover in the operationalization of the SGS, the associations observed between desirable green space characteristics and health are difficult to interpret in simple land cover terms since single land parcels may contribute varying weight to the summative SGS ordinal measure (for further details see Skärbäck, et al., 2012). Furthermore, the SGS takes account only of the presence/absence of land parcels with desirable characteristics, and not how much or little of a residential area these comprise. The current study builds upon this approach by accounting for the amount as well as the presence of different types of green space environment (although limited to land cover measures only).

The theme of our research was thus whether mental health is better in rural areas with greater amounts of certain types of land cover, and we had three specific research questions. First, we explored whether the positive association found between mental health (General Health Questionnaire) and the quantity of green space (compared to built-up areas) in urban areas would extend to rural areas. The measure used for this includes Saltwater, Freshwater and Coastal land cover in addition to types of vegetation, and therefore we refer to it as 'natural space' rather than 'green space'. Second, and perhaps most importantly, we investigated whether the make-up of green space in rural areas would be related to mental health. For instance, compared to built-up land, would the amount of woodland (O'Brien and Morris, 2013) or coastal margins (White et al., 2013b) be more positively related to mental health than other land cover types such as arable land or saltwater estuary? Our work was 
exploratory, in the sense that we began with the idea that different types of rural land cover may have different relationships to mental health, perhaps due to their different amenity, aesthetic or biodiversity characteristics, rather than with more specific directional hypotheses. Finally, a robustness check on these outcomes was conducted to see whether the operationalization of the GHQ measure, as an interval scale or 'caseness' score (see below), might influence results.

\section{Methods}

Measures of exposure to classes of natural space were derived using GIS to link the land parcel classification of Land Cover Map 2007 (Morton et al., 2011) to English rural residential areas. Natural land cover types were expressed as a proportion of total residential area land cover. British Household Panel Survey (BHPS) data collected between 1991 and 2008 (Taylor, et al., 2010) were used to derive estimates of associations between the land cover characteristics of residential areas and mental health as measured by the General Health Questionnaire (GHQ) for people living in rural areas.

\section{Sample}

The sample consisted of 2,020 individuals drawn from the larger BHPS who: a) were resident in English rural neighbourhoods, i.e. areas classified by morphology as 'Village and Dispersed', as opposed to either 'Small Town and Fringe' or 'Urban' by the Office for National Statistics in 2005 using the methodology described by Bibby and Shepherd (2004); and b) had full data on the outcome and predictor variables, for at least one wave. Due to the longitudinal nature of the study, individuals were repeatedly interviewed over several years so each individual could have multiple 'observations'. In the sample we used here there were 12,697 observations pertaining to 2,020 individuals (mean number of observations per individual $=6.3$ ). It is these observations that are used in subsequent statistical analyses and enable us to simultaneously compare results both between different 
individuals and within the same individuals over time. The observations used in the estimation amount to $61.6 \%$ of a total 20,600 BHPS observations of individuals in rural residential areas of England. Observations where covariate data were missing were excluded from analyses.

Rural status was derived from the classification of the Lower-level Super Output Area (LSOA; boundaries defined in 2001) in which individuals lived. The rural status designated in 2005 was carried across to all waves of data 1991-2008; it is unlikely that any areas are misclassified as rural since that would require either an area previously classified as a small town or as urban to have become a village by the time of the 2005 classification, or for the morphology of a village to have changed immediately after 2005. However, it is possible that a small number of areas were rural at earlier times in the panel but are excluded from the analysis by this decision rule, as villages grew into small towns by 2005 .

LSOAs are a standard residential area unit used in the UK to report small area statistics, and are defined to encompass areas with approximately 1,500 residents; the mean area of the 2,946 rural LSOAs in England is $30.8 \mathrm{~km}^{2}$. The 12,697 estimation observations were $52.40 \%$ female; mean age 47.59 years old; $72.73 \%$ married or living with a partner; $59.65 \%$ in employment and $21.14 \%$ retired (see Supplementary Table 1 for full details). The observations of BHPS respondents from rural England that could not be included in the sample $(n=7,903)$ had a greater proportion of females $(56.99 \%)$, and less people in employment (54.04\%) and more in retirement (26.02\%) than the estimation sample, but were only slightly older, with a mean age of 48.74 years old, and there were no other differences of note. Thus caution is required in the interpretation of the current results as representative of the rural population.

Importantly, of the total sample, 214 individuals relocated from one rural area to another during their time in the panel. This meant that that these individuals had potential change in 
both a) the land cover make-up of the areas in which they resided and b) their mental health. Due to the longitudinal nature of the panel this sub-sample was associated with 1,867 observations ( $M=8.7$ observations per person) which could thus be examined for withinindividual differences. Descriptive statistics for this subset of the estimation sample observations were examined to determine whether they were different in important ways from the full set of estimation sample observations. These observations were $51.74 \%$ female; mean age 42.17 years old; $79.33 \%$ married or living with a partner; $72.09 \%$ in employment and $9.80 \%$ retired. (see Supplementary Table A for full details). Thus, the subsample of the estimation sample observations from which within-individual land cover effects were estimated were, on average, younger, more likely to be in employment, and less likely to be retired, than the full set of estimation sample observations. Not all of the 214 individuals who relocated between rural areas experienced change on all land cover classes; much relocation was both from, and to, areas with zero coastal land cover, for example. The sample size from which within-individual effects of each specific land cover type are estimated, are presented with results.

\section{Measures}

\section{Land cover}

The current research used the ten aggregate land cover classes in the Land Cover Map 2007 (LCM2007; Morton, et al., 2011): Broadleaf woodland; Coniferous woodland; Arable; Improved grassland; Semi-natural grassland; Mountain, heath and bog; Saltwater; Freshwater; Coastal; and Built-up areas (including gardens). Although LCM2007 also provides a finer grained 23 category taxonomy of land cover types, it is less reliable, and the ten categories were deemed sufficient for present purposes. LCM2007 maps land cover types across the UK using $25 \mathrm{~m}$ grid cells. The map is created by classifying summer-winter composite satellite images of polygons. A spatial framework based on generalised digital 
cartography, and also on agricultural census data, is used to ensure that the map is constructed from polygons which represent meaningful real-world land parcels, such as fields and plots of woodland.

In the current study, GIS areal interpolation (Flowerdew et al. 1991) was used to assign the $25 \mathrm{~m}$ grid cells of LCM2007 to LSOAs. The percentage of each LSOA comprised of each of the ten land cover classes was then calculated. LCM2007 includes an Unclassified category which was disregarded from the percentage base; when assigned to LSOAs, only 169 of the 2,946 rural LSOAs included some unclassified land, which accounted for $M=0.0565 \%$ land cover in the LSOAs affected, $(S D=0.1246 \%)$. Finally, these LSOA land cover percentage measures were linked to the BHPS sample observations based on residential area LSOA.

Descriptive data on the mean proportions of the ten land cover classes for both all rural LSOAs in England, and for the estimation sample observations, are presented in Table 1. In addition, a measure of generic natural space was derived by collapsing all the land cover categories except Built-up land; we thus define 'natural space' to include Freshwater, Saltwater, Coastal etc. rather than limiting the definition to a narrower subset of land cover categories comprising green vegetation, which might more commonly be grouped together as generic green space. There are no differences of note between the mean proportions of the land cover classes, or generic measure, amongst the estimation sample, and the sample of all rural LSOA, and in this respect the residential areas of the panel respondents living in rural areas are broadly typical of such residential areas nationwide.

\section{Mental health}

Mental health was measured with the short form, 12 item General Health Questionnaire (GHQ-12), a widely used and reliable self-assessment screening tool to aid clinical diagnosis of mood disorders such as anxiety and depression (Goldberg, et al., 1997). It is also commonly used as a measure of positive mental health in epidemiological research with 
population samples and is robust to re-test effects (Pevalin, 2000). Respondents are asked to consider how the "past few weeks" compared to "usual" in terms of 6 positive and 6 negative states e.g. coping. For each item there are four ordinal response options, scored 0 , 1,2 or 3 . Item scores were summed to give interval scale scores in the range $0-36$; the scale was reversed in the current study so that higher GHQ scores as we report them (i.e. inverseGHQ) represent better mental health. The estimation sample observations ( $n=12,697)$ had a mean GHQ score of 25.10 ( $S D=5.19)$, showing on the average, good mental health.

As a robustness check, mental health was also operationalised from GHQ-12 item responses using a second standard scoring method (Goldberg and Williams, 1988) to derive an indicator outcome variable. The two item responses considered to reflect low risk of poor mental health were scored 0 , and the two considered to reflect a higher risk of poor mental health were scored 1 . These item scores were summed to give totals in the range 0 , very good mental health, to 12 , very poor mental health, (estimation sample mean $=1.702$; $\mathrm{SD}=$ 2.844), and a categorical measure of poor mental health or 'psychiatric caseness' was defined as a score $\geq 3$. This 'caseness' criterion is met by $2,951(23.24 \%)$ of the estimation sample observations.

\section{Control variables}

Regression models included control variables at both area and individual levels, for factors known to be related to GHQ (Dolan, et al., 2008). LSOA level controls were taken from the English Indices of Deprivation, (ID 2010 release; Department of Communities and Local Government, 2008), and linked to the sample observations based on residential area LSOA: income deprivation (derived from social benefit data); employment deprivation (derived from unemployment data); education deprivation (derived from school performance data, participation rates in higher education and working age adult qualifications data); and crime (derived from crime records). Individual level control variables included factors known to be 
related to $\mathrm{GHQ}$, and factors that may change upon relocation and so potentially confound the effects of land cover: Age category (25 and under; $26-35 ; 36-45 ; 46-55$ - reference category; 56-65; 66-75; over 75); Diploma/degree level qualified; Married/living with a partner; Living with an own child aged under 16; Household income operationalized as the log of net annual household income in the preceding 12 months adjusted for household composition using the Before Housing Costs equivalence scale, and indexed to January 2010 prices (Jenkins, 2010); Work-limiting health; Labour market status (employed/selfemployed - reference category; unemployed; retired; in education/training); Residential accommodation (detached house - reference category; semi-detached house; terraced house; flat; other); Accommodation size (less than 1 room/person; 1 - less than 3 rooms/person - reference; 3 or more rooms/person); Commuting time (non-commuter reference category;15 minutes and less; 16-30 minutes; 31-50 minutes; over 50 minutes); and Fixed time effects (indicator variables for BHPS data collection waves).

\section{Analytic Approach}

Regression analyses were conducted using the xt suite of functions in Stata 12 (StataCorp, College Station, TX). Random Effects (RE) regression was used to estimate the effects of land cover on GHQ interval scale scores. Separate estimates were derived based on differences between the mean scores of different individuals (between-individual effects), and based on scores for the same individuals at different points in time where individuals relocated from one rural area to another and so had within-individual variation on the land cover variables of interest (within-individuals effects). These separate effects estimates were derived by inclusion in the model of individual mean values for all independent variables (Schunck, 2013; Rabe-Hesketh and Skrondal 2008). The model for GHQ can be expressed by

$G H Q_{i j}=\beta 0+\beta \bar{X} 1_{i}+\beta \bar{X} 2_{i}+\beta\left(X 1_{i j}-\bar{X} 1_{i}\right)+\beta\left(X 2_{i j}-\bar{X} 2_{i}\right)+\left(\mu 0_{j}+\varepsilon_{i j}\right)$ 
where $\beta 0$ denotes the model intercept; $i=1,2, \ldots n$ denotes the individual respondent; $j=1$, 2, ... $n$ denotes the observation for the individual; $G H Q_{i j}$ denotes the GHQ response for observation $j$ for individual $i ; \bar{X} 1_{i}$ denotes the mean values of the set of land cover exposure measures for all observations for individual $i ; \bar{X} 2_{i}$ denotes the mean values of the set of individual and area level control measures for all observations for individual $i ; X 1_{i j}$ denotes the set of land cover exposure measures for observation $j$ for individual $i$; and $X 2_{i j}$ denotes the set of individual and area level control measures for observation $j$ for individual $i$. Then, the between-individual effects of land cover exposure are given by $\beta \bar{X} 1$, and the withinindividuals effects of land cover exposure are given by $\beta(X 1-\bar{X} 1)$. The significance of differences between the estimated within-individual and between-individual effects was tested by substituting in the model, non-individual mean centred values, in place of individual mean centred values:

$G H Q_{i j}=\beta 0+\beta \bar{X} 1_{i}+\beta \bar{X} 2_{i}+\beta X 1_{i j}+\beta X 2_{i j}+\left(\mu 0_{j}+\varepsilon_{i j}\right)$

so that the difference in the within-individual and between-individual effects of land cover exposure are given by $\beta \bar{X} 1$ (Rabe-Hesketh and Skrondal 2008; Schempf and Kaufman, 2012).

The estimated within-individual effects of land cover control for personality, upbringing and other stable factors which may influence both an individual's mental health and where he or she chooses to live. Importantly, in the multiple land cover model, we follow Mourato et al. (2010) in omitting the Built-up land cover category. The regression coefficients therefore represent the scale point change in GHQ for a percentage point increase in a given land cover type whilst decreasing by a percentage point the share of Built-up land cover, when other independent variables (including other land cover types) are held constant.

\section{Results}

Post-review pre-publication draft. Published as Alcock, I., White, M.P., Lovell, R., Higgins, S.L., Osborne, N.J., Husk, K., Wheeler, B.W., 2015. What accounts for 'England's green and pleasant land'? A panel data analysis of mental health and land cover types in rural England. Landscape and Urban Planning 142, 38-46. 


\section{Generic natural space}

The initial exploratory analysis examined natural space, which is broadly comparable to a generic green space measure. The between-individuals estimate of this measure had no significant relationship with GHQ; a $1 \%$ natural space increase was associated with a 0.01 scale point increase in $\mathrm{GHQ}(\mathrm{SE}=0.02 ; \mathrm{p}=.619)$. However, a significant association was found from the within-individuals estimate, where a $1 \%$ natural space increase was associated with a 0.092 scale point increase in $\mathrm{GHQ}(\mathrm{SE}=0.04 ; \mathrm{p}=.021)$. This result was robust to the caseness measure, where no significant between-individuals effect was observed, but the estimate from within-individual differences showed a $1 \%$ increase in natural space was associated with decreased odds of achieving psychiatric caseness $(\mathrm{OR}=$ $0.954 ; \mathrm{SE}=0.02 ; \mathrm{p}=.025)$. Thus, despite relatively high levels of green and other natural space in all rural areas and the lack of any relationship between the neighbourhood natural space density of different individuals and their mental health, increases in rural natural space experienced by individuals were associated with significant benefits to mental health.

Subsequent analyses investigated whether this relationship was driven by all non-Built land, or whether the different types of rural land cover were differentially related to withinindividual change in mental health.

\section{Land cover types}

Estimates for the main model, which specified simultaneous entry of the land cover classes, are summarised in Table 2 (see Supplementary Information Table 2 for full details). The between-individual estimates showed no significant associations between any land cover type and mental health. However, the within-individual estimates showed significant $(p<.05)$ positive associations with Arable, Improved grassland, Semi-natural grassland, Mountain, heath and bog, and with Coastal land cover. The relative benefits of these types of land cover over Built-up land, adjusted for their prevalence, can be compared by examining the 
scale point increases in the $0-36 \mathrm{GHQ}$ measure associated with $1 \mathrm{SD}$ increases in these land covers: Arable, 1.988; Improved grassland, 2.363; Semi-natural grassland, 0.763; Mountain, heath and bog, 1.116; Coastal, 1.463 (Table 2). Furthermore, a significant negative association was observed with Saltwater, with a 1 SD increase associated with a decrease in GHQ of 0.346 scale points. The relationships estimated from differences between individuals regarding GHQ and the Improved grassland, Mountain, heath and bog, Coastal and Saltwater land cover classes, were significantly different from those estimated from differences within-individuals at different times.

\section{$\underline{\mathrm{GHQ}}$ robustness check}

A robustness check for the main model examined relationships between the land cover types and the GHQ caseness binary outcome (Supplementary Table 3). Within-individual estimates showed significantly lower odds ( $p<.05$, compared to the Built up category) of reporting psychiatric caseness to be associated with Broadleaf woodland, Improved grassland, Semi-natural grassland and Coastal land cover, and significantly higher odds associated with Saltwater, whilst the lower odds associated with Mountain, heath and bog were marginally significant $(p=.055)$. The main model estimates from within-individual differences of significant benefits to mental health associated with the grassland land cover classes and Coastal land cover, were therefore found to be robust to the caseness measure, but the estimated benefit of Mountain, heath and bog was statistically weaker. The effect of Saltwater on mental health observed in the main model was also robust to the caseness measure. However, the significance of beneficial relationships with Arable and Broadleaf woodland differed when the interval scale and binary GHQ outcomes were regressed against them, with Arable significantly associated only with the former, and Broadleaf woodland significantly associated only with the latter. The lack of significant associations from between-individual estimates in the main model was replicated in the robustness check. 


\section{Discussion}

\section{Summary of results}

GIS was used to link high spatial resolution land cover data in ten classes (e.g. woodlands, arable) to rural LSOAs in England to enable a novel analysis of relationships with an indicator of mental health. Relationships were estimated for a longitudinal sample of residents of rural LSOAs, some of whom moved from one rural area to another and so had different land cover exposure at different times. By specifying individual mean values on predictor variables in conjunction with individual mean-centred values, separate effects estimates for both natural space and a set of rural land cover types were derived from between-individual differences and within-individual differences at different times.

Natural space was positively related to good mental health when estimated from withinindividual differences, supporting the hypothesis that even in rural residential areas levels of green and other natural space can be associated with this wellbeing measure. The main model suggested different relationships between different types of land cover and mental health. Replicating earlier findings which included both urban and rural areas (White et al., 2013b), individuals who moved home during their time in the panel (i.e. within-individual effects) showed better mental health in years when they were living in areas with more coastal land such as beaches. In contrast, and unreported by previous work, Saltwater land cover including mudflats exposed when tidal rivers are at low tide, had a negative withinindividuals effect, although it must be noted that the samples from which within individual effects of Coastal and Saltwater were estimated were very small (only 412 observations from 46 individuals, and 351 observations from 37 individuals, respectively). The 'open' landscapes found where land cover was Improved or Semi-natural grassland, or Mountain Heath and Bog, also showed positive within-individual effects. As these land cover types will potentially afford wide views to relatively distant horizons, this is consistent with the 
Prospect-Refuge theory of landscape preference (Appleton, 1984). Arable also showed positive within-individual effects, though this was not robust to the caseness measure.

Confidence in these results comes from the estimation of associations with sociodemographic covariates from both between-individual and within-individual variation which replicate previous findings (Supplementary Information Table 2; Dolan et al., 2008; White et al., 2013a). Examples include the significant positive associations between mental health and being employed rather than unemployed, and the significant negative associations with having a work-limiting health condition rather than not.

\section{Links to other research}

In general, the green land cover types associated with mental health improvements within individuals were consistent with the results of the Swedish research using the Scania Green Score. Whilst the detail of the SGS derivation is complex and involves other inclusion criteria (Skärbäck, et al., 2012), the SGS operationalised desirable qualities in natural environments in terms of categories from the Swedish Corine Landcover Project (SCLP; Ahlcrona, et al., 2001). Ten categories of SCLP land parcel which were considered to offer desirable recreational qualities will be listed, and their likely equivalent LCM2007 aggregate class will be stated where this is not obvious; it will be noted that the LCM2007 equivalents of these categories showed evidence of positive association with good mental health: 1) 'Non-urban parks', (classified as Improved grassland by LCM2007); 2) 'Pastures', (classified as Improved grassland by LCM2007); 3) 'Broad-leaved forest'; 4) 'Mixed forest'; 5) 'Natural grassland'; 6) 'Moors and heathland'; 7) 'Thickets'; 8) 'Open spaces with little or no vegetation', (which includes beaches, classified as Coastal, and bare rock, classified as Mountain, heath and bog by LCM2007); 9) 'Wetlands', (which include marshes, classified as Semi-natural grassland, and salt marshes, classified as Coastal by LCM2007); and 10) 'Inland water'. With the exception of the LCM2007 Freshwater land cover category, which is 
scarce in England, the LCM2007 equivalents of these SCLP categories showed evidence of positive association with good mental health, although significant association with the LCM2007 Broadleaf woodland category was only with the caseness measure. The SCLP classes which are specifically excluded from the SGS are 'Artificial surfaces', (classified as Built-up by LCM2007); 'Coniferous forest'; 'Arable', though there are exceptions to this where ancient farmland is environmentally protected; 'Permanent crops', (classified as Arable by LCM2007); and 'Marine' waters. Again, there is some consistency here with our findings, since the LCM2007 category Coniferous woodland had no significant association, and Saltwater had a negative association.

Our within-individual findings are also consistent with the research literature on landscape preferences. Preferences are not trivial, since, from an evolutionary perspective, organisms adapt to enable them to survive and reproduce in landscape types where they are able to exploit resources. Thus, it is argued that despite variation in people's expressed preferences according to factors such as prior experience, culture and demographics, landscape preferences indicate settings in which people are more likely to function effectively (Kaplan and Kaplan, 1989). It is for this reason that preferences drive decisions we make in life, such as, for instance, where we choose to live. Some studies have demonstrated that people tend to prefer parkland and savannah-like landscapes (Falk and Balling, 2010), and similar types of open, lightly wooded, green landscape have been idealised throughout human civilisation (Ward Thompson, 2010). When asked to categorise images of environments, some of the most consistent differentiation is between 'wild' and more ordered and managed landscapes (Hartig and Evans, 1993), suggesting that degree of human influence is relevant in people's responses. For instance, van den Berg and Koole (2006) and de Groot and van den Born (2003) reported that wild landscapes were generally rated more beautiful than managed landscapes. Similarly, a Norwegian study (Kaltenborn and Bejerke, 2002) of preferences in a 
rural community found images with features such as mountains, forests and lakes, were rated as most attractive, and modern agriculture received the lowest ratings.

Preferences for different agricultural landscapes have also been compared. Examining Swiss alpine landscapes, Lindemann-Matthies, et al. (2010) found low-intensively managed, species-rich grassland were rated highest, and mere production landscapes with highintensity grassland and arable land were rated lowest. In addition, a Northern Ireland study found images of 'traditional' farming landscapes, which included grassland categories, were preferred over 'intensive' agriculture, which included arable categories, (Howley, et al., 2012). In sum, this research tradition indicates the unpopularity of more managed and specifically arable landscapes, in contrast to the popularity of land cover such as grassland, which may have savannah-like characteristics. These preference trends are broadly consistent with associations we observed between land cover and positive mental health amongst those relocating between rural areas. Whilst Arable land cover, which is excluded from the SGS, was associated with good mental health compared to Built-up land cover, (on the interval scale measure only), the within-individual beneficial effects associated with an increase in Arable were substantially below those associated with the grassland categories. For instance, using the current data, a planned comparison test which specified Arable rather than Built-up as the reference showed that a 1\% increase in Improved grassland over Arable was associated with an increase of $0.0519 \mathrm{GHQ}$ scale points ( $\mathrm{SE}=0.0178 ; \mathrm{p}=.004)$.

\section{Accounting for the observed contrast in the between and within individual effects}

Given previous findings on landscape preferences, and the within-individuals estimates, we are unsure why land cover was not related to differences in mental health between individuals. One possibility is that differences in the two samples contributed to these estimates. It was noted above that those relocating between rural areas are younger and more likely to be in employment, and possibly this difference is important in this respect. 
They may also differ in factors which are not controlled in the models. A potentially relevant factor is residential area attachment, which is related to mental health (Pevalin, 2003; O'Brien et al., 1994), and may also be related to land cover. It may be, for instance, that neighbourhood attachment was lower amongst those who re-located and, precisely because of this, it was these individuals who sought to move to an area they would like more and which would make them happier. This is speculation at this point however, and further work is needed to understand the motivations behind why people do or do not move to different areas, and to specific environment types.

Another possibility is that psychological adaptation (Diener, 2006) occurs after one has lived in an area with positive land cover features (e.g. broadleaf woodlands and coastal) for a number of years and thus the between individual differences become smaller the longer people have lived in the same area. Adaptation was not observed within a three-year period following increases in urban green space amongst intra-urban movers, but adaptation was observed following reductions in green space (Alcock et al., 2014), and it might be that adaptation to land cover change does occur in rural areas. Again, it would be interesting to see how long our movers would need to live in their new areas before adaptation may occur.

Finally, a third reason why between-individual effects were not found may be, in part, statistical. Specifically, individual heterogeneity was not accounted for in the between participant estimates and it may be that this is an important omission. For instance, it may be that by not controlling for things such as upbringing and personality, there is simply too much 'noise' in the data for any effects of land cover type to emerge. This would be particularly important if there was indeed a difference in upbringing or other non-observed factors which were influencing both where individuals lived and their mental health. For example, if certain types of people with generally better mental health lived in areas with less woodland, this might, at the aggregate level, mask a statistically significant beneficial effect of living near woodlands for those with poorer mental health. Thus one may not see a difference in land 
cover because there are important non-observed differences in people who reside in different areas.

\section{$\underline{\text { Implications and limitations }}$}

Despite the lack of between individual effects, the evidence from the within-individual estimates that different types of green land cover are differentially related to mental health in rural areas has potential implications for the framing of policy designed to maximise health benefits from natural environments. Current planning and health promotion policies emphasise increasing access to generic green space in urban areas; see, for example, Department of Health (2011) in the UK, and the American Public Health Association draft policy statement on Nature, Health and Wellness in the US. The policy focus to date on generic green space in urban areas doubtless follows, in part, from the research evidence pointing to the importance of exactly this. It would also be fair to point out that it is in the urban parts of economically developed nations that large proportions of the population, as well as the burden of disease amongst them, are concentrated. Furthermore, green space in urban areas is often a threatened or dwindling resource in many countries, creating a pressing need for evidence-based urban planning policy which can work in conjunction with health policy (Lee and Maheswaran, 2010).

However, policies which address generic green space may, by definition, neglect important contributions from natural environments to health in rural areas. Whilst generic green space covers a far greater proportion of rural LSOAs than urban LSOAs in England, (mean 96.16\% versus $27.82 \%$ ), the nature of 'green space' differs markedly. Urban green space in the UK is typically characterised by parks with grassland and trees, gardens (which may be included as a component in generic green space), and small pockets of undeveloped natural habitats, allotments, roadside verges and river corridors. Arable is a category of green landscape which dominates many rural residential areas but is a relatively minor constituent of urban 
green space. In other words, policy references to urban green space are often to improved grassland, whereas references to rural green space are more likely to be to arable land. A more nuanced policy approach might acknowledge the importance of the nature of green space in rural areas.

Despite the strengths of our analysis, we recognise a number of limitations. The analysis considers only main effects. Cumulative or synergistic effects of different land cover types were beyond the scope of this study. Further, LCM2007 measures of land cover collected between 2005 and 2008 (Morton, et al., 2011) are linked to individual respondent data collected between 1991 and 2008. Longitudinal change in land cover is therefore not accounted for. In addition, the level of geographical resolution used in the production of LCM2007 means that the distribution maps have a degree of simplification, since only UK land parcels over $5,000 \mathrm{~m}^{2}$ are classified and mapped, with smaller parcels 'dissolved' into the surrounding landscape. Moreover, this study is premised on the assumption that residential area land cover is a valid proxy measure for individual exposure. No measures were available from the BHPS data of factors relevant to this assumption, such as how much time respondents spent out of doors. Whilst LSOA is a typical unit of analysis used in this type of research (Mitchell and Popham, 2008), there are also drawbacks related to the use of LSOA as the residential unit, since rural LSOAs vary greatly in size; amongst the estimation sample observations, these areas had $\mathrm{M}=29.5 \mathrm{~km}^{2}$ and $\mathrm{SD}=23.4 \mathrm{~km}^{2}$. Thus, whilst the average residential area within which land cover is operationalised is an area with a radius of approximately $3 \mathrm{~km}$, a residential area boundary used in previous research on green space and health (Maas, et al., 2006), some individuals are linked to land cover data from substantially larger areas. Furthermore, areas are not equidistant buffers around residences, so that the land cover linked to one individual may be mainly to the north of the home, whilst that linked to another may be mainly to the south, etc. This lack of consistent definition of the land cover exposure variables arises from the use of an LSOA level dataset 
which was prepared for another purpose, and any bias resulting from this is unknown. Future research might use a much more precise exposure proxy based on the derivation of buffers around residential postcodes.

Although one strength of the analysis is that the within-individual estimates control for factors such as personality, a weakness is that the sample of individuals who contribute to these estimates was relatively small, and it would be inappropriate to assume them to be representative of the population. Moreover, even in the case of a representative sample, it is important to note that within-individual estimates would not permit inference to a sampled population. The successor survey to the BHPS, the Understanding Society panel survey, has a much larger sample, and over time the subsample of individuals who engage in the relatively rare event of relocation from one rural area to another will be larger in this panel than in the BHPS, allowing estimates to be based on a greater number of observations as well as allowing increased understanding through sample stratification on demographic factors such as age and socio-economic status. A further limitation is that whilst the withinindividual estimates control for time-invariant individual effects, we were unable to control for all potentially relevant time varying factors, especially at the area level, and so these effects cannot be assumed to be causal effects.

\section{Conclusion}

This research focused on land cover in rural residential areas, and so provided a context where green space is more varied than in urban areas which are usually the setting for research in this field. Land cover data on residential areas was linked through GIS to repeated measures of individuals' mental health status. Natural space in rural areas was found to be positively related to good mental health when estimated from within-individual differences. The results from re-locating individuals also offer some evidence that different types of green and other natural space offer different degrees of benefit to human wellbeing. 
However, no evidence in support of this hypothesis emerged from comparing land cover exposure between individuals. These results, and the inherent limitations in the study design, underline the need for further research to better inform land development policies.

\section{Acknowledgements}

The ECEHH (part of the University of Exeter Medical School) is supported by investment from the European Regional Develop-ment Fund and the European Social Fund Convergence Programmefor Cornwall and the Isles of Scilly. This work was supported by the Economic and Social Research Council [grant numberES/K002872/1] and was carried out as part of a wider project considering relationships between health and wellbeing and environmental type and quality, 'Beyond Greenspace’ (http://beyondgreenspace.

wordpress.com). The research was also funded by the National Institute for Health Research Health ProtectionResearch Unit (NIHR HPRU) in Environmental Change and Health at the London School of Hygiene and Tropical Medicine in partnershipwith Public Health England $(\mathrm{PHE})$, and in collaboration with the University of Exeter, University College London, and the Met Office. Neither the BHPS data collectors nor the UK Data Archive bear any responsibility for the analyses or interpretations presented here.The views expressed are those of the authors and not necessarily those of the NHS, the NIHR, the Department of Health or Public Health England. We thank Erik Skärbäck for help in understanding the SGS, and Reinhardt Schunck and three anonymous reviewers for helpful comments on earlier drafts.

\section{Appendix A.}

Supplementary data associated with this article can be found,in the online version, at http://dx.doi.org/10.1016/j.landurbplan.2015.05.008 


\section{References}

Ahlcrona, E., Olsson, B. and Rosengren, M. (2001) Swedish Corine Landcover. In Groom, G. and Reed, T. (Eds.) Strategic Landscape Monitoring for the Nordic Countries. Copenhagen: TemaNord. 95-99.

Alcock, I., White, M. P., Wheeler, B. W. Fleming, L. and Depledge, M. H. (2014) Longitudinal effects on mental health of moving to greener and less green urban areas. Environmental Science and Technology, 48(2), 1247-1255.

Annerstedt, M., Östergren, P. O., Björk, J., Grahn, P., Skärbäck, E. and Währborg, P. (2012) Green qualities in the neighbourhood and mental health - results from a longitudinal cohort study in Southern Sweden. BMC Public Health, 12:337 doi:10.1186/1471-2458-12-337.

Antonakis, J., Bendahan, S., Jacquart, P. and Lalive, R. (2010) On making causal claims: a review and recommendations. The Leadership Quarterly, 21, 1086-1120.

Appleton, J. (1984) Prospects and refuges revisited. Landscape Journal 3(2), 91-103.

Astell-Burt, T., Mitchell, R., and Hartig, T. (2014) The association between green space and mental health varies across the lifecourse: A longitudinal study. Journal of Epidemiology and Community Health, 68(6), 578-583.

Beyer, K. M. M., Kaltenbach, A., Szabo, A., Bogar, S., Nieto, F. J. and Malecki, K. M. (2014) Exposure to neighborhood green space and mental health: evidence from the survey of the health of Wisconsin. International Journal of Environmental Research and Public Health, 11(3), 3453-3472.

Bibby, P. and Shepherd, J. (2004) Developing a New Classification of Urban and Rural Areas for Policy Purposes - the Methodology. Retrieved March 172015 from 
http://archive.defra.gov.uk/evidence/statistics/rural/documents/rural-defn/rural-urbanmethod.pdf

Björk, J., Albin, M., Grahn, P., Jacobsson, H., Ardö, J., Wadbro, J., Östergren, P. O. and Skärbäck, E. (2008) Recreational values of the natural environment in relation to neighbourhood satisfaction, physical activity, obesity and wellbeing. Journal of Epidemiology and Community Health 62(4), e2.

Blake, W. (1804) Milton, a Poem in 2 Books. [Privately printed by the author]: London.

de Groot, W. T. and van den Born, R. J. G. (2003) Visions of nature and landscape type preferences: an exploration in The Netherlands. Landscape and Urban Planning, 63(3), 127138.

de Jong, K., Albin, M., Skärbäck, E., Grahn, P. and Björk, J. (2012) Perceived green qualities were associated with neighborhood satisfaction, physical activity, and general health: results from a cross-sectional study in suburban and rural Scania, southern Sweden. Health \& Place, 18(6), 1374-1380.

Department of Communities and Local Government (2008) The English Indices of Deprivation 2007. Department of Communities and Local Government: London.

Department of Health (2011) Healthy Lives, Healthy People: Our strategy for public health in England. London: HM Government.

de Vries, S., Verheij, R. A., Groenewegen, P. P. and Spreeuwenberg, P. (2003) Natural environments-healthy environments? An exploratory analysis of the relation- ship between greenspace and health. Environment and Planning A, 35(10), 1717-1731.

Diener, E., Lucas, R. E., and Scollon, C. N. (2006) Beyond the hedonic treadmill: revising the adaptation theory of well-being. American Psychologist 61(4), 305-314. 
Dolan, P., Peasgood, T., and White, M. P. (2008) Do we really know what makes us happy? A review of the economic literature on the factors associated with subjective well-being. Journal of Economic Psychology, 29(1), 94-122.

Falk, J. H. and Balling, J. D. (2010) Evolutionary influence on human landscape preference. Environment and Behavior, 42(4), 479-493.

Flowerdew, R., Green, M., and Kehris, E., (1991). Using areal interpolation methods in geographic information systems. Papers in Regional Science 70, 303-315.

Goldberg, D. P. and Williams, P. (1988) The User's Guide to the General Health Questionnaire. Ist Edition. Windsor: NFER-Nelson.

Goldberg, D., Gater, G., Sartorius, N., Ustun, T., Piccinelli, M., Gureje, O., Rutter, C. (1997) The validity of two versions of the GHQ in the WHO study of mental illness in general health care. Psychological Medicine, 27(1), 191-197.

Gunnell, D., Wheeler, B., Chang, S. S., Thomas, B., Sterne, J. A. C., Dorling, D. (2012) Changes in the geography of suicide in young men: England and Wales 1981-2005. Journal of Epidemiology and Community Health 66(6), 536-543.

Hartig, T., and Evans, G. W. (1993) Psychological foundations of nature experience. In Garling, T. and Golledge, R. G. (Eds.), Advances in psychology: Vol. 96: Behavior and environment: Psychological and geographical approaches. Amsterdam: North-Holland. 427457.

Hartig, T., Mitchell, R., de Vries, S. and Frumkin, H. (2014) Nature and health. Annual Review of Public Health 35, 207-228.

Howley, P., Donoghue, C. O. and Hynes, S. (2012) Exploring public preferences for traditional farming landscapes. Landscape and Urban Planning, 104(1), 66-74. 
Jenkins, S. P. (2010) The British Household Panel Survey and its income data. ISER

Working Paper 2010-33. Retrieved May 20th, 2012, from

http://www.iser.essex.ac.uk/publications/working-papers/iser/2010-33.pdf

Jorgensen, A. and Gobster, P. H. (2010) Shades of green: measuring the ecology of urban green space in the context of human health and well-being. Nature and Culture 5(3), 338363.

Kaltenborn, B. P. and Bjerke, T. (2002) Associations between landscape preferences and place attachment: a study in Roros, southern Norway. Landscape Research, 27(4), 381-396.

Kaplan, R. and Kaplan, S. (1989) The experience of nature: A psychological perspective. New York: Cambridge University Press.

Lee, A. C. K. and Maheswaran, R. (2010) The health benefits of urban green spaces: a review of the evidence. Journal of Public Health, 33(2), 212-222.

Lindemann-Matthies, P., Briegela, R., Schupbach, B. and Junge, X. (2010) Aesthetic preference for a Swiss alpine landscape: the impact of different agricultural land-use with different biodiversity. Landscape and Urban Planning, 98(2), 99-109.

Maas, J.,Verheij R. A., Groenwegen, P., de Vries, S. and Spreeuwenberg, P. P. (2006) Green space, urbanity, and health: how strong is the relation? Journal of Epidemiology and Community Health, 60(7), 587-592.

Maas, J.,Verheij, R. A., de Vries, S., Spreeuwenberg, P., Schellevis, F. G., and Groenwegen, P. P. (2009) Morbidity is related to a green living environment. Journal of Epidemiology and Community Health, 63(12), 967-973.

Mitchell, R. and Popham, F. (2007) Greenspace, urbanity and health: relationships in England. Journal of Epidemiology and Community Health, 61(8), 681-683. 
Mitchell, R. and Popham, F. (2008) Effect of exposure to natural environment on health inequalities: an observational population study. The Lancet, 372(9650), 1655-1660.

Morton, D., Rowland, C., Wood, C., Meek, L., Marston, C., Smith, G., Wadsworth, R. and Simpson, I. C. (2011) Countryside Survey: Final Report for LCM2007 - the new UK Land Cover Map. CS Technical Report No 11/07. (CEH project number: C03259). Centre for Ecology \& Hydrology, Natural Environment Research Council: Wallingford.

Mourato, S., Atkinson, G., Collins, M., Gibbons, S., MacKerron, G. and Resende, G. (2010) Economic assessment of ecosystem related UK cultural services. The Economics Team of the UK National Ecosystem Assessment, London School of Economics, London.

O’Brien, D. J., Hassinger, E. W. and Dershem, L. (1994) Community attachment and depression among residents in two rural Midwestern communities. Rural Sociology 59, 255265.

O'Brien, L., and Morris, J. (2013) Well-being for all? The social distribution of benefits gained from woodlands and forests in Britain. Local Environment 19(4), 356-383.

Ord, K., Mitchell, R., and Pearce, J. (2013). Is level of neighbourhood green space associated with physical activity in green space? International Journal of Behavioural Nutrition and Physical Activity 10, 127. doi:10.1186/1479-5868-10-127.

Pevalin, D. (2000) Multiple applications of the GHQ-12 in a general population sample: an investigation of long-term retest effects. Social Psychiatry and Psychiatric Epidemiology, 35(11), 508-512.

Pevalin, D.J. (2003) Intra-household differences in neighbourhood attachment and their associations with health. In: Morgan A, ed. Social capital for health: insights from quantitative research. London: Health Development Agency, 2003. 
Rabe-Hesketh, S. and Skrondal, A. (2008) Multilevel and Longitudinal Modelling Using Stata 2nd Ed. Stata Press: College Station, Texas.

Riva, M., Curtis, S., Gauvin, L. and Fagg, J. (2009) Unravelling the extent of inequalities in health across urban and rural areas: Evidence from a national sample in England. Social Science \& Medicine, 68(4), 654-663.

Schempf, A. H. and Kaufman, J. S. (2012) Accounting for context in studies of health inequalities: a review and comparison of analytic approaches. Annals of Epidemiology 22, 683-690.

Schunck, R. (2013) Within and between estimates in random-effects models: Advantages and drawbacks of correlated random effects and hybrid models. Stata Journal 13(1), 65-76.

Skärbäck, E., Wadbro, J., Bjork, J., de Jong, K., Albin, M., Ardo, J. and Grahn, P. (2012) The agricultural landscape for recreation. In Aflakbui, G. (Ed.) Agricultural Science. Intech: Rijeka. 225-242.

St Leger, L. (2003) Health and nature - new challenges for health promotion. Health Promotion International, 18(3), 173-175.

Takano, T., Nakamura, K., and Watanabe, M. (2002) Urban residential environments and senior citizens' longevity in megacity areas: the importance of walkable green spaces. Journal of Epidemiology and Community Health, 56(12), 913-918.

Taylor, M. F.; Brice, J.; Buck, N. and Prentice-Lane, E. (2010) British Household Panel Survey User Manual Vol. A: Introduction, Technical Report and Appendices. University of Essex: Colchester, UK.

Ulrich, R. S. (1984). View through a window may influence recovery from surgery. Science, 224(4647), 420-421. 
van den Berg, A. E. and Koole, S. L. (2006) New wilderness in the Netherlands: An investigation of visual preferences for nature development landscapes. Landscape and Urban Planning, 78(4), 362-372.

van den Berg, A. E., Koole S. L., and van der Wulp, N. Y. (2003) Environmental preference and restoration: (How) are they related? Journal of Environmental Psychology, 23(2), 135146.

van den Berg, A. E., Maas, J., Verheij, R. A., and Groenewegen, P. P. (2010) Green space as a buffer between stressful life events and health. Social Science and Medicine, 70(8), 1203-1210.

Ward Thompson, C. (2010) Linking landscape and health: The recurring theme. Landscape and Urban Planning, 99(3), 187-195.

Weich, S., Twigg, L., and Lewis, G. (2006) Rural/non-rural differences in rates of common mental disorders in Britain: prospective multilevel cohort study. British Journal of Psychiatry, $188,51-57$

White, M. P., Alcock, I., Wheeler, B. W. and Depledge, M. H. (2013a) Would you be happier living in a greener urban area?: A fixed effects analysis of panel data. Psychological Science, 24(6), 920-928.

White, M. P., Alcock, I., Wheeler, B. W. and Depledge, M. H. (2013b) Coastal proximity and health: a fixed effects analysis of longitudinal panel data. Health \& Place, 23, 97-103.

Figure Figure title $\quad$ Page 
Table 1. Land cover by LCM2007 aggregate class and total natural space

(mean percentage) of all English LSOAs, and of estimation sample observations.

Table 2 Estimation sample descriptive data, and random effects regression

estimates of GHQ (0-36) in rural areas against LCM2007 aggregate

land cover classes 
Table 1. Land cover by LCM2007 aggregate class and total Generic green space (mean percentage) of all English LSOAs, and of estimation sample observations.

\begin{tabular}{|l|ll|ll|}
\hline LCM2007 aggregate class & \multicolumn{2}{|l|}{$\begin{array}{l}\text { Rural LSOAs }(\mathrm{n}=2,946) \\
\text { Mean \% land cover (SD) }\end{array}$} & $\begin{array}{l}\text { Estimation sample } \\
\text { observations }(\mathrm{n}=12,697) \\
\text { Mean \% land cover (SD) }\end{array}$ \\
\hline Broadleaved woodland & 8.21 & $(7.66)$ & 8.97 & $(9.36)$ \\
Coniferous woodland & 1.77 & $(3.88)$ & 1.41 & $(2.61)$ \\
Arable & 46.92 & $(23.56)$ & 43.72 & $(23.91)$ \\
Improved grassland & 29.63 & $(16.21)$ & 32.10 & $(17.49)$ \\
Semi-natural grassland & 6.20 & $(6.27)$ & 6.58 & $(5.00)$ \\
Mountain, heath and bog & 2.40 & $(7.75)$ & 2.43 & $(6.69)$ \\
Saltwater & 0.02 & $(0.14)$ & 0.03 & $(0.14)$ \\
Freshwater & 0.59 & $(1.86)$ & 0.63 & $(1.33)$ \\
Coastal & 0.43 & $(2.84)$ & 0.31 & $(1.75)$ \\
Total Generic 'natural & 96.16 & $(5.76)$ & 96.19 & $(5.31)$ \\
space'a & & $(5.35)$ & 3.81 & $(5.31)$ \\
Built-up areas and gardens & 3.84 & &
\end{tabular}

${ }^{a}$ Aggregates all the LCM2007 aggregate classes except: Built-up areas (including gardens). 
Table 2. Estimation sample descriptive data, and random effects regression estimates of GHQ (0-36) in rural areas against LCM2007 aggregate land cover classes ${ }^{\mathrm{a}} ; \mathrm{n}$. obs. $=12,697 ; \mathrm{n}$. individuals $=2,020$.

\begin{tabular}{|c|c|c|c|c|c|c|c|c|c|c|c|}
\hline & \multirow{2}{*}{$\begin{array}{l}\text { Estimation } \\
\text { sample } \\
\text { SD }\end{array}$} & \multicolumn{4}{|c|}{$\begin{array}{l}\text { Between-individual effects (individual } \\
\text { mean variables) }\end{array}$} & \multicolumn{5}{|c|}{$\begin{array}{l}\text { Within-individual effects (individual mean-centred } \\
\text { variables) }\end{array}$} & $\begin{array}{l}\text { Significance of } \\
\text { difference in } \\
\text { within- and } \\
\text { between- } \\
\text { individual } \\
\text { effects }\end{array}$ \\
\hline & & coeff & (SE) & $p$ & $\begin{array}{l}\text { Effect of } \\
1 \mathrm{SD} \\
\text { change }\end{array}$ & $\begin{array}{l}\text { Within- } \\
\text { individual } \\
\text { difference } \\
\mathrm{N} \\
\text { individuals } \\
\text { ( } \mathrm{N} \text { obs.) }\end{array}$ & coeff & (SE) & $\mathrm{p}$ & $\begin{array}{l}\text { Effect of } \\
1 \mathrm{SD} \\
\text { change }\end{array}$ & $p$ \\
\hline Broadleaved woodland & 9.36 & 0.0071 & 0.0271 & .794 & 0.063 & $214(1867)$ & 0.0803 & 0.0616 & .192 & 0.721 & .282 \\
\hline Coniferous woodland & 2.61 & -0.0248 & 0.0465 & .594 & -0.065 & $208(1817)$ & 0.0766 & 0.0712 & .282 & 0.200 & .234 \\
\hline Arable & 23.91 & 0.0115 & 0.0211 & .587 & 0.274 & $214(1867)$ & 0.0831 & 0.0369 & .024 & 1.988 & .097 \\
\hline Improved grassland & 17.49 & 0.0052 & 0.0219 & .811 & 0.092 & $214(1867)$ & 0.1351 & 0.0396 & .001 & 2.363 & .005 \\
\hline Semi-natural grassland & 5.00 & 0.0321 & 0.0334 & .337 & 0.161 & $214(1867)$ & 0.1524 & 0.0615 & .013 & 0.763 & .097 \\
\hline Mountain, heath and bog & 6.69 & -0.0041 & 0.0266 & .877 & -0.028 & $193(1667)$ & 0.1667 & 0.0738 & .024 & 1.116 & .027 \\
\hline Saltwater & 0.14 & 0.3398 & 0.7027 & .629 & 0.049 & 37 (351) & -2.4219 & 1.1305 & .032 & -0.346 & .035 \\
\hline Freshwater & 1.33 & -0.0289 & 0.0693 & .677 & -0.038 & 195 (1712) & 0.4700 & 0.3545 & .185 & 0.625 & .173 \\
\hline Coastal & 1.75 & 0.0298 & 0.0818 & .716 & 0.052 & $46(412)$ & 0.8380 & 0.3318 & .012 & 1.463 & .019 \\
\hline
\end{tabular}


${ }^{a}$ Coefficients in columns 2 and 6 represent fitted change in GHQ score for a 1\% increase in land cover classes (within and between individuals respectively) and a corresponding 1\% decrease in urban land cover, and columns 5 and 9 represent fitted change in GHQ score for a 1 SD (see column 1) increase in land cover classes; model includes controls for: Government office region; Area income deprivation; Area employment deprivation; Area education deprivation; Area crime deprivation; Age; Education; Marital status; Parenting status; Household income; Work-limiting health; Labour market status; Residential accommodation; Commuting; Fixed time effects. 